Open Access

\title{
Intimate power: the intergenerational cooperation and conflicts in childrearing among urban families in contemporary China
}

\author{
Suowei Xiao@
}

Correspondence: xiao@bnu.edu.cn School of Social Development and Public Policy, Beijing Normal University, Beijing, China

\begin{abstract}
This article examines the cooperation and conflicts in the "intergenerational parenting coalition," the practice of joint caregiving by parents and grandparents that is prevalent among contemporary urban Chinese families. The author argues that a pattern of "yan mu ci zu" (grandparents feed, mothers teach) has emerged in the intergenerational parenting coalition. Specifically, young mothers act as powerful "managers" of the childrearing project, while grandparents serve primarily as caretakers who are marginalized in family power relations. Differing from the institutionalized power structure in traditional Chinese families, yan mu ci zu is a set of fluid, uninstitutionalized power relations constrained by negotiations and bargaining between family members and mediated by intergenerational intimate relations.
\end{abstract}

Keywords: Intergenerational parenting coalition, Intergenerational cooperation, Yan mu ci zu, Intimate power

\section{Introduction}

In western societies, particularly the USA, the majority of grandparents follow a norm of noninterference in intergenerational relationships and do not assume a central role in caring for or rearing grandchildren (Cherlin and Furstenburg 1986). Their involvement with grandchildren may increase when their adult children face difficulties, such as unemployment, bankruptcy, divorce, incarceration, or drug abuse (Gibson 2005). By contrast, in contemporary China, it is a prevalent phenomenon for grandparents to participate in care of the grandchildren. According to the China Health and Nutrition Survey in their pooled sample drawn from nine provinces from 1991 to 2004, 45 \% of grandparents coresided with children aged zero to six. In families where three generations coresided, grandparents, especially grandmothers, played an extremely important caregiving role, spending a similar amount of time on childcare of preschool-aged children as the mothers did. Nonresidential grandparents also served as important alternative childcare providers. In $27 \%$ of surveyed families, children were cared for at paternal grandparents' households and nearly $13 \%$ at maternal grandparents' households (Chen et al. 2011). Other large sample surveys in urban China also indicate that

(c) 2016 The Author(s). Open Access This article is distributed under the terms of the Creative Commons Attribution 4.0 International License (http://creativecommons.org/licenses/by/4.0/), which permits unrestricted use, distribution, and reproduction in any medium provided you give appropriate credit to the original author(s) and the source, provide a link to the Creative Commons license, and indicate if changes were made. 
more than half of the respondents receive help with childrearing from their or their spouse's parents (Goh and Kuczynski 2010; Ma et al. 2011).

China has a long history of grandparents' involvement in taking care of grandchildren. Historians note that in traditional Chinese society most young couples lived with the husband's family when their children were born; grandparents, as well as other female relatives, played an important role in raising the young children (Xiong 2008). However, departing from the traditional image that old people simply enjoyed playing with grandchildren, the contemporary intergenerational collaboration in childrearing is more complicated in nature. On the one hand, grandparents' participation in raising the grandchildren constitutes an important source of support for adult children, helps cultivate a close relationship with their grandchildren, and enhances their satisfaction in life (Goh and Kuczynski 2010). On the other hand, however, contradictions and conflicts regarding childrearing issues occur frequently between the grandparents and their adult children. Due to differences in parenting styles and beliefs, nurturing and educating the grandchildren is likely to result in conflicts in the intergenerational parenting coalition (Goh and Kuczynski 2010, 2012; Luan 2009). Grandparents and their adult children also engage in a delicate competition for intimate bonds with the children (Shen 2013). A few scholars have noted the tendency for grandparents to become "nannies" in the intergenerational parenting coalition, i.e., they take on the lion's share of the housework and childcare while giving up their voice in family decision-making (Goh and Kudznski 2010; Shen 2013).

These findings indicate that contemporary intergenerational parenting coalitions not only present a continuance of the traditional intergenerational cooperation but also reveal a new feature regarding intergenerational relations and the changing power relations between generations in particular. By studying the intergenerational parenting coalition, this study seeks to address the following questions: In the contemporary intergenerational collaboration of childcare in urban China, what is the division of labor and power relations between the family members regarding childrearing affairs? Is there an emerging pattern of intergenerational power relations and how is it challenged and maintained between family members? With an in-depth investigation into the intergeneration cooperation and conflicts in childrearing, this article seeks to deepen the understanding of power relations in intergenerational cooperation and assistance and illuminate the intertwining power and intimacy in the family.

This article draws on in-depth interviews and observations of parents and grandparents who collaborated in raising grandchildren between 2010 and 2013. The analysis focuses on 13 families residing in Beijing at the time of the research. All of the parents in this study had a junior college degree or higher. The majority of the fathers held professional or managerial positions or had their own business. Most mothers worked or had worked in research, managerial, or administrative jobs such as secretary or accounting. ${ }^{1}$ The household annual income was no less than 150,000 yuan ( $\approx$ US $\$ 22,869)$. In only one family were the parents born in Beijing; all the others had migrated to work and had purchased private homes in Beijing. Twelve out of the 13 children in the participating families had Beijing hukou (household registration). Ten out of the 13 children in the participating families were aged between 3 and 6 years old, and the other three were school aged (7 to 10 years old). Except for one family in which the grandparents lived apart and were not involved in childcare, all the other families had three 
generations living under the same roof for more than 1 year and the grandparents provided childcare in varying forms on a daily basis.

I conducted multiple interviews that lasted between 3 and $6 \mathrm{~h}$ in total with all 13 mothers and one 2-h interview with two fathers, respectively. I asked the parents to elaborate on their childrearing experiences since the birth of their children. This paper focuses on the preschool years when grandparents were most likely to be involved in childrearing. Complementing the parent sample, eight grandparents who engaged in caring for their grandchildren were also interviewed. All of these grandparents lived in Beijing, were between 60 and 80 years old, and had stable incomes at the time of the interview. In addition, I also visited the homes of seven of the participating families and joined three families for weekend trips, which enabled me to observe the interactions between different family members and better understand the family dynamics. For confidential reasons, all names used in this article are pseudonyms.

\section{Intergenerational cooperation in the family in reform-era China}

Intergenerational cooperation and reciprocity is an important tradition in Chinese families. Culturally speaking, familism is a value system that maintains and enhances the stability of Chinese society, of which the family is the basic unit. Family members and kin linked by blood ties have a unique closeness toward each other by nature and undertake unconditional and unlimited responsibilities and obligations of mutual care and support (Liu 2013). Since the market reform, along with the nuclearization of the family and the prevalence of the independence of an adult son's conjugal family from his natal family in residence, property, and finance, parents and their adult children have shifted from intrafamily to interfamily relations and intergenerational relations have become the connection between two nuclear families (Wang 2010). The tradition of mutual support and aid across generations has persisted; the parental family is closely connected with the adult children, which constitutes a new pattern of "[nuclear] families in [kin] networks" (Wang 2010; Ma 2011). The existing literature on intergenerational cooperation and reciprocity has primarily concerned two dimensions, i.e., resource flow and cultural ethics.

First, in regard to the resource flow, extensive attention has been drawn to fairness in the intergenerational exchange of economic, physical, and emotional means. Some researchers argue that the pattern of intergenerational cooperation and reciprocity is "reciprocal" or "feeding back" (fanbu), i.e., adult children maintain close reciprocal exchanges with their parents and tend to provide more economic resources and caregiving to their parents than the other way around (Xiong 1998; Xu 2011; Bian et al. 1998). Others point out that adult children, singletons in particular, receive extensive financial, emotional, and physical support from their parents, which may exceed what they provide to their parents. This is referred to metaphorically as "en wangxia liu" (downstream grace) or "yanlei wangxia liu" (tears dripping down) (He 2009; Ma et al. 2011; Liu 2005; Liu 2012; Shen 2013). In recent years, the rising phenomenon of ken lao (i.e., adult children being dependent on their elderly parents for financial, physical, and other forms of support) and the tragic cases of children neglecting to properly provide for their rural elderly parents have aroused much debate on whether the equilibrium and fairness in the traditional "feeding back" model of intergenerational exchange has been altered (Guo 2001; He 2009; Liu 2012). 
Second, regarding cultural ethics, the central issue concerns the change in the ethical foundations of intergenerational cooperation. Some scholars point out that traditional family ethics that emphasize responsibility and obligations between family members has faded, and ideas are emerging under the veil of individualism that stress the subjectivity of the younger generation (Liu 2012; Kang 2012; Shen 2013; Yan 2003). Nevertheless, there is a difference in the two generations' views of family ethics. Some studies find that the elder generation still holds a firm sense of "responsibility-oriented ethics," i.e., they fulfill their responsibilities and obligations toward their descendants, generously offering support and assistance to their children (and grandchildren) through various means, as well as attempting to lessen their children's burden to provide them with elderly care and being forgiving when the children do not "feed back" in a proper manner (Yang and He 2004). However, other scholars argue that despite the fact that the elder generations selflessly support their children, they no longer stick to the notion of unlimited responsibilities and obligations (Liu 2013). More debates concerning the younger generations' notion of family ethics have been generated. Informed by individuation theories, one group of scholars argues that family has become the pool of resources and means with which individuals achieve their personal goals, and the basis of intergenerational ties has shifted from mutual obligation to individual desire, choices, and needs (Shen 2013; Yan 2003, 2012). Other studies challenge the abovementioned view of the "individuation of the family," arguing that emotional ties still predominate in nuclear families while economic benefits outweigh family ethics in intergenerational relations (Tan 2010). The term "new familism" has been coined, referring to the family notions held by the younger generation that seeks to accommodate both personal and family interests. The author argues that adult children, while growing a strong sense of individualism, value the family as a whole as well and are willing to maintain a mutually supportive relationship with their parents (Kang 2012).

To better understand the mechanism and process of intergenerational cooperation, another dimension of power relations between generations is essential yet understudied in the existing literature. The few exceptions include Shen's study of urban families in Shanghai. This work finds that in families where three generations lived under the same roof, young mothers were relieved from most of the housework and had more power in making decisions and arranging family affairs, while the grandparents relinquished their authority. She claims this is a reversal in the power relations of the parent-child axis (Shen 2013). This particular study examines power in intergenerational relations from a relatively static view, highlighting the shift in the relative position and status of grandparents and parents in the family that resulted in changes in the resources, rights, responsibilities, and obligations of the two generations. However, as scholars of family studies have pointed out, family politics is a dynamic process; constantly negotiating their interests and demands with one another. Individuals seek a greater voice and respect in family affairs and tend to achieve their goal by accumulating moral capital and strategizing in family politics (Wu 2009; Zheng and Yang 2003).

Viewing power as dynamic and flowing is illuminating for understanding power relations in the contemporary intergenerational parenting coalition. In the modern transition of Chinese families, the traditional patriarchal family power structure relying on hierarchies of gender, generation, and age has been challenged. On the one hand, the cultural and moral authority granted to parents through their status in the family has 
weakened, the power of the younger generation is on the rise, and women's, especially young women's, status in the family has been enhanced (Ma et al. 2011; Shen 2009; Wang 2009; Xiao 2002; Yang 2011). On the other hand, the institutionalized and welldefined hierarchy between family members has loosened. The weakening of the institutionalized power structure gives room to negotiations between family members and a more-flexible and diversified power relation in the family (Wu 2009; Shen 2013; Yan 2012). In other words, in the traditional family where rules of seniority and hierarchy were strictly enforced, individual power was closely linked with one's institutionalized role and status in the family, with little room left for individual maneuvering. In contrast, in the modern family with a relatively loose hierarchical structure, individuals have more space to maneuver in search for their voice in family affairs. For instance, a recent study found that many parents subsidized their children's purchase of housing, either by making initiatives or positively responding to their children's request, in order to establish a "negotiative intimacy" with the latter (Zhong and Ho 2014). By willingly providing financial resources, parents captured the chance to take part in their children's family affairs and cultivate a desirable relationship with them characterized by emotional exchange, respect, and close ties. This finding challenged the stereotypical image of parents being "the victim" and "disadvantaged" as they sponsor their children's real estate pursuits.

With a close examination of the intergenerational parenting coalition, this article seeks to illuminate the characteristics of intergenerational power relations in contemporary China, highlighting both the general power structure and dynamic process of exercising power. I argue that in the intergenerational parenting coalition a new pattern of yan ти сi zu has emerged concerning both the division of labor and the power structure between generations. To be specific, young mothers act as powerful "managers "of the childrearing project, and grandparents serve primarily as caretakers who are marginalized in the family power relations. However, the intergenerational power relations in the yan mu ci zu pattern is uninstitutionalized but fluid, susceptible to the negotiations and interactions between family members and largely confined by the construction and maintenance of specific intimate relations between parents and the grandparents.

I thus use the concept of "intimate power" to describe the particular features of the exercise of power in the intergenerational parenting coalition, highlighting the connection between intimate relations and power in the family. The concept of intimate power includes the following three aspects. First, in the intergenerational collaboration, the establishment of intimate relationship between family members is the premise of the exercise of power. Second, individual exercise and negotiation of power is mediated by intimate relations between family members. Finally, as in the specific case of the intergenerational parenting coalition, grandparents give up their negotiations in authority and power so as to sustain mutual assistance and cooperation as well as emotional intimacy with their offspring.

The rest of the article covers two main themes: the division of labor and power relations in the intergenerational parenting coalition and intimate relations and the exercise of power in childrearing. A brief discussion of the transition in childrearing in modern China is presented in order to help readers understand the background under which the contemporary intergenerational parenting coalition has formed. 


\section{The modern transition of childrearing in China}

The Chinese tradition in childrearing was highly functionally oriented. The child's main task was to learn to behave as a person, growing up into a socially recognized adult so as to honor his/her family and ancestors, and perpetuate the family line. Early child training was characterized by respecting seniors, being pragmatic and moral, and discipline (Xiong 2008). Yan fu ci mu (mothers feed, fathers teach) was the common pattern in childcare: mothers were responsible for biophysical care, i.e., physically bringing up the young with daily feeding, dressing, and tenderness. They empathized with the children's bodily and emotional needs and formed intimate bonds with them. Fathers were responsible for sociocultural reproduction, taking over the training in children's moral and behavioral requirements as well as intellectual skills. The affection between the father and the child were thus inhibited. Paternal grandparents and female relatives were also involved in the daily care of children since most young couples were coresiding with the husband's family when they became parents (Fei 1998; Xiong 2008).

The modern transition of Chinese society has brought enormous changes in childcare practices. In the pre-reform socialist era, children were seen as the future of the nation rather than private property of the family. Attempts were made to reorganize childcare in a collective way. In the cities, public kindergartens and childcare facilities were set up to alleviate the family's burden of childcare. A large number of women entered the labor force, but the gender division of labor in the family persisted. In general, urban women suffered the double burden of work and housework/caregiving and relied on kin networks for support in caregiving (Zuo and Jiang 2010).

Since the market reform, there has been a trend of marketization and privatization in childrearing. With the decrease of public childcare facilities, families resumed the primary if not sole responsibility of raising children. Discussions concerning parenting have also proliferated since the reform. The first parenting magazine A Must Read for Parents was founded at the beginning of the 1980s and introduced a new concept of "parents" as referring to those who adopt scientific methods to foster the healthy development of their children (Dong 2014). In recent years, popular readers on family education have proliferated. Informed by western child development psychology, they advocate for good parenting that changes from adult centered to child centered, from exam oriented to cultivating comprehensive qualities. The new views stress the importance of providing early education, engaging in emotional communication, and cultivating interests in the child (Chen ed. 2005). These popular views of childrearing in the name of scientific parenting have been well received by young urban parents, especially the newly emerged middle-class families. Furthermore, due to the one-child policy and the intensified market competition since the reform, many parents have high expectations of upward mobility for their children and seriously invest in their children's education (Lin 2009; Fong 2004). Along with the burgeoning markets for children's education and consumption, raising the child has become a complicated project that involves parents, schools, experts, and markets. First, parental roles are extended. Good parents are not only caretakers of their children but also learners of parenting skills and consumers of the educational market. They actively acquire new knowledge and skills to perceive and respond to their children's needs. Furthermore, they also attentively seek information about nutrition and education; choose desirable educational institutions, toys, books, and consumer products; and arrange appropriate activities for their children. 
Second, childrearing has become consumer oriented and highly costly. Parents seek not only to facilitate their children's development by purchasing professional educational services but also to cultivate class-coded lifestyle and tastes in their children through adopting consumption patterns. Taking the families who participated in my study as an example, except for one mother who worked in a university and was thus able to send her son to the public kindergarten affiliated with her university at an affordable price, all the other families chose to send their children to private kindergartens which cost an average of 2500 yuan ( $\approx \mathrm{US} \$ 381$ ) per month (varying from 1800 yuan to 4200 yuan). Other educational expenses, such as early child-development programs, extracurricular activities, and private tutoring, totaled over 1500 yuan ( $\approx$ US \$229) per month on average. Parents also pay attention to what their children eat and wear. Rather than simply feeding their children and keeping them warm, they want things of good quality and taste for the little ones. For instance, some parents regularly purchase expensive organic food and fashionable outfits for their children. Children's social and leisure activities such as birthday parties, vacation trips, and summer camps have become an important part of the household expenses. ${ }^{2}$

As childrearing becomes more complicated and expensive, families need enormous labor and financial resources to provide "proper" care for their children. This care has been divided into different sets of tasks, including mental work such as learning, selecting, decision-making, teaching, and playing; manual work such as taking physical care of the children; and auxiliary work such as cooking, washing clothes, and house cleaning.

\section{Yan mu ci zu: the division of labor and power relations in childrearing}

Among the middle-class families that participated in this study, the pattern of yan mu ci $z u$ (grandparents feed, mothers teach) has emerged regarding the division of labor in the intergenerational parenting coalition. Specifically, mothers become the manager, taking full charge of all childrearing affairs and assume the responsibilities of sociocultural reproduction. Grandparents become helpers and engage in biophysical care but lack authority in childrearing and family affairs. Fathers concentrate on earning the financial resources to facilitate their children's development but are largely absent from their children's everyday life. However, they do participate in decision-making via their connection with the mothers. Therefore, yan mu ci zu not only reflects the principle of labor division in childrearing but also illuminates the power relations between different family members in the parenting coalition. However, young mothers do not have the institutionalized symbolic and moral resources to ensure their leading role and authority in childcare-related affairs. There is much room for negotiation between family members, who strategize to change or maintain the particular pattern of power relations in the family. In this sense, the power relations in the intergenerational parenting coalition are flexible and diversified. The case of Meimei's family below presents an excellent example.

\section{The intergenerational collaboration in childrearing in Meimei's family}

Meimei was a 4-year-old girl. Since her birth, her grandparents from both sides rotated to help care for her. Meimei's maternal grandmother first came to help until she was 8 months of age, and then her paternal grandparents took over. After Meimei went to 
kindergarten at the age of two and a half, her maternal grandparents returned since the paternal grandparents were no longer able to provide childcare due to health conditions. Since they had another daughter who also needed childcare help the old couple had to separate, with each one staying with one daughter's family and then rotating on a regular basis. They made it clear to their daughters that if they were needed, they would be happy to come, but if not, they would not insist.

At the time of the research, the grandfather was living with Meimei's family. Every morning, he was the first one to get up. He prepared breakfast for the family and then took Meimei to kindergarten at 8:00 a.m. He then did the grocery shopping, cleaned the apartment, and washed the clothes. At noon, he fixed himself a quick lunch, took a nap, and then started preparing dinner and snacks for Meimei. At about 5:00 p.m. he picked up Meimei from kindergarten. When they got home, he watched her while she was playing and cooked dinner at the same time. On most days, the grandfather would wait for everyone to return home for the family dinner. However, sometimes he and Meimei ate alone because his daughter and son-in-law were home very late. After dinner, if his daughter was home, he would go out for a walk; if not, he would skip the daily exercise.

With the help of the grandparents, Meimei's mother, Yang, earned her $\mathrm{PhD}$ and completed a 2-year postdoc appointment. She then took a teaching position in a small private college although she had other job offers. The couple made this decision collectively after deliberate discussion. Working in a small college did not earn much salary, but it allowed Yang to take care of the family because of its flexible schedule, two 1-month breaks and relatively low demands for research and publications compared to research universities. Yang read extensively on topics related to childrearing, such as Parenting Encyclopedia, A Good Mother Is More Important than a Good Teacher, Capturing Children's Sensitive Periods, and Effective Parent Training. She also followed childrearing information and discussions on online forums and attended lectures given by education professionals. She stated that she was not very concerned about practical things such as her daughter's future career; her principle was "learning how to be a good person is the top priority and other things such as learning knowledge comes later."

At preschool age, Yang focused on nurturing Meimei's emotional stability and cultivating her communication skills. For instance, when Meimei was fussy and began crying and screaming, Yang would neither cajole nor scold her; instead, she would hold her gently and reason with her when Meimei calmed down. Sometimes Meimei was fussy for quite a while, and Yang had to try very hard to stay patient. When Yang was disciplining Meimei, the grandparents normally kept silent and left them alone. However, Yang's mother was short-tempered and would "help" discipline the child in ways that Yang did not agree with, such as using mandatory language or intimidating the child. Yang could not help complaining and often asked her to leave.

Most days, Yang got home before 6:00 p.m. and had dinner with Meimei. After that, the mother and daughter played games, sang songs, drew pictures, read books, or visited neighborhoods together. At 9:00 p.m., Yang helped Meimei get ready for bed by brushed her teeth, washed her face, and reading bedtime stories. After Meimei's first birthday, Yang began to arrange outdoor activities for the family on weekends. The parents took Meimei to parks, museums, swimming pools, organic farms, and so on. The grandparent(s) 
sometimes joined them for weekend activities as well. Yang had to make considerable efforts to arrange these outings, checking the venue, getting directions, checking the weather and other details in advance, and informing the father about the arrangements.

Yang was concerned about finding a good kindergarten for her daughter from the time Meimei was born. Over the past few years, she had sought out information from Web sites and online forums, as well as from neighbors and friends. When Meimei was about 2 years old, Yang began contacting kindergartens that she was interested in. In 1 year, she became well informed about all the kindergartens in a 5-mi radius of their residence, attended more than ten related presentations organized by the kindergartens, and visited six kindergartens in person. Her top choice was a private school because the principal's ideas on education resonated with her. She took her husband to the campus visit, and both were quite satisfied with the facilities and the teachers. However, the high expense of 3600 yuan ( $\approx$ US \$549) per month made her hesitate. ${ }^{3}$ Her husband helped her decide by saying, "You won't be able to get a good education by choosing a cheap one."

When Meimei tuned 2 years old, Yang signed her up for art, dance, and English classes. Meimei liked to paint, so Yang sent her to a painting class recommended by other mothers. Meimei attended dance classes because Yang liked dancing and found that Meimei had a good sense of rhythm. Yang also sent Meimei to English classes because most of her neighbors' and friends' children of Meimei's age were learning English. Meimei's father was also enthusiastic about his daughter learning English at an early age, but it was Yang who called English training centers for information and audited three different classes with Meimei. Yang did not expect her daughter to be an artist or a dancer in the future; rather, these classes made good use of her daughter's time by learning useful skills and cultivating good taste. The total cost of these art and language classes as well as kindergarten added up to over 6000 yuan ( $\approx$ US \$915) per month, which exceeded Yang's salary.

Fortunately, Meimei's father made a good salary. After working for consulting companies for over 10 years, he earned more than 200,000 yuan ( $\approx$ US \$30,492) annually, which he attributed to his hard work, including regularly working overtime and taking business trips. During Meimei's first year of life, he was working on a project in another city and only came back home about every 2 weeks. Yang commented, "At that time, I could not count on him [to take care of the baby]. He had changed the diaper only once or twice and recorded it because he thought it was interesting. But if I asked him to do it [change the diaper] every day, no way!" Meimei's father later began to resent the fact that his job kept him away from home and found a new job that enabled him to work in Beijing for most of the time, taking only one or two short business trips each month. Although he was able to come back home every day, the father still had little time to spend with Meimei. On the few days that he finished work early, he arrived home at around 8:00 p.m. He would play with Meimei after dinner, doing somersaults or putting her on his neck. "They are just like friends," Yang commented. The father and the daughter had about half an hour of fun before it was time for Meimei to go to sleep. However, for most of the nights, Meimei was already asleep when her father got home.

Although Yang had some complaints, she was generally satisfied with her husband for being the primary breadwinner of the family and making an effort to be a good father. He did not have much face-to-face interaction with Meimei, but his wife kept him informed about the child, and he would regularly talk to Meimei over the phone 
when he was away on business trips. When it came to important decisions such as choosing a kindergarten or leisure activities, the father would be involved, sharing his thoughts, providing suggestions, and even making the final decision when the mother was hesitating. In the past year, under the influence of the mother, the father had improved: he tried not to work on weekends and would join the family for outdoor activities or take Meimei to different classes. He even spent several weekends joining other parents to prepare a show that would be performed for all the children in the kindergarten on International Children's Day.

\section{The division of labor in childrearing}

Meimei's case reveals the common rules of the intergenerational division of labor in childrearing among most of the families in this study. As the managers of the childrearing project, young mothers engage in three main responsibilities.

First, differing from the traditional maternal role that concentrated on caretaking, the primary responsibility of the mother involves making plans and decisions for her child's development, from selecting educational organizations to arranging daily activities. These decisions include choosing a kindergarten, early childhood education programs, and leisure activities; making arrangements for weekends and holidays; and shopping for food, clothes, and toys that are age appropriate for her child. To make better decisions, mothers have to invest enormous time and effort in collecting and analyzing relevant information, surfing the Internet, reading books, talking with other mothers, and consulting experts, as well as taking field trips.

The second role is educating and training the child, which includes two main parts. To better the intellectual development of the child, mothers engage in various activities such as reading to the child, assessing and cultivating the child's talents, and developing and maintaining relationships with kindergartens and training centers. Furthermore, mothers are also concerned about building good character and habits in their children. Modern childrearing ideas emphasize self-discipline, emotional management, communication skills, and adaptive habits. Training for these characteristics is integrated into the process of daily caretaking. To achieve these goals, mothers not only discipline the child, setting rules and regulating the child's behavior, but also monitor others who take part in childcare.

The third responsibility is taking care of the child's daily life. The extent to which mothers are personally caring for the physical needs of the child varies from one family to another and is related to the intensity of the mother's paid work, health condition of co-caretakers (grandparents in particular), and, most importantly, the mother's perceptions of whether certain interactions are important to the child's development. Like Yang, most mothers interviewed bathed their child and put them to bed themselves because they believed these were key activities in building intimate bonds between the mother and the child.

Grandparents are responsible for taking physical care of the child and performing the household chores, such as doing grocery shopping, cooking, cleaning the house, washing the clothes, taking the grandchildren to school, and bringing them back home. In some families, grandparents have extra tasks such as preparing special children's meals and feeding them, giving them a bath, and putting them to sleep. For instance, before Yangyang turned three, his mother took business trips on a regular basis. Yangyang was thus cared for mainly by his maternal grandmother. Three-year-old Yuanyuan was 
allowed to choose to co-sleep with her grandparents or her parents each night; whoever Yuanyuan co-slept with was responsible for getting her cleaned up before going to bed and dressed when getting up.

Grandparents also serve as the safety nets in childrearing. The division of labor between the mother and the grandparents is usually defined but not strictly enforced. Most of the time, to accommodate the mother's schedule, grandparents willingly undertake more tasks than were originally "assigned" to them to ensure that the grandchild is well cared for. For instance, in Meimei's family, it was usually the mother who played with the child after dinner; however, if the mother got home late, the grandparents would automatically "work" overtime to take care of the child.

Departing from the traditional image of an authoritative figure in the family, the fathers in this study had shifted from rule enforcers to playmates with their children, spending quality time and having fun. Being a playmate indicates an important feature of the "new fathers," a paternal ideal that has emerged in recent years. Unlike authoritative father figures, "new fathers" are more involved in childrearing and engage in faceto-face interactions and emotional communication with their children (Wang 2014; Lamb 2000). However, among the interviewed families, fathers had limited time to spend with their children. On workdays, only two of the 13 fathers spent more than an hour with their children; the father-child quality time took place mainly on weekends or holidays. Not all fathers were like Meimei's father who reserved his weekends for the family; quite a few of them gave priority to their work and joined other family members on weekend activities only when they did not have to work overtime.

In addition to being playmates, fathers also act as backup or supplementary helpers in times of emergency. For example, fathers would attend parent-teacher meetings when mothers were unavailable, take a sick child to the hospital, or discipline the children for difficult issues (usually upon mothers' persistent requests). These situations only occurred occasionally, in contrast to the everyday routine duties of childcare and discipline performed by mothers and grandparents. When it comes to important decisions regarding children's education, such as choosing a kindergarten or talentcultivating program, many fathers get involved by offering their thoughts. That said, mothers discuss the situation with fathers and solicit the father's opinion. If they disagree with one another, however, it is usually the mother who has the final say. ${ }^{4}$

Largely absent from providing daily care for their children, the father's main responsibility is to provide financial resources for the expensive child development plans that mothers make. Most of the families that participated in this study were dual wageearners; both parents worked and made significant financial contributions to the family. However, many families tend to follow the traditional conceptions of gender division of labor in the family in which the man serves as the primary breadwinner. Driven by the high cost of modern childrearing, the role of the father is highlighted by their financial provision for children's development, which to some extent rationalizes their absence from children's daily life. ${ }^{5}$

\section{Intergenerational power relations}

The case of Meimei's family also illuminates a particular power relation between the parents and grandparents in the intergenerational parenting coalition, i.e., young 
mothers dominate while the grandparents are marginalized in decision-making and handling of matters related to childrearing. As the manager of the childrearing project, young mothers are in charge of decision-making, from those related to children's formal education to the arrangements of the child's daily life. In addition, mothers enjoy more discursive power. On matters such as providing proper care and training and cultivating the child's talents, the mother's opinion shapes how things should be perceived and handled, which is largely attributed to their active learning of popular methods of scientific parenting. As a result, young mothers assume the role of supervising other family members and intervene when the latter handle the child in an inappropriate way. For instance, as illustrated in Meimei's family, Yang asked her own mother to stay away when the latter was trying to help discipline the child. In other families, it was not unusual for mothers to monitor the behavior of other family members. In Daodao's family, the mother made a no smoking rule at home for the sake of the child's health. If the father wanted to smoke, he had to go outside. Two-year-old Jingjing insisted on someone holding him and rocking him to sleep. His mother believed this was a bad habit and felt she had to correct the grandmother who kept doing this. The child cried and screamed for hours when the mother was training him to lie down and go to sleep by himself. Out of sympathy, the grandmother interceded, but the mother criticized her, saying, "Letting him be [without proper training] is to spoil the child."

Fathers partially participate in decision-making, especially concerning important matters of the child's development. However, unlike the traditional authoritative paternal role, in the interviewed families, fathers were more of a participant and counselor in the process rather than the primary decision-maker. Fathers have the right to be informed and share their opinion. However, their opinions matter only if they successfully make an impact on their wives' thoughts and/or feelings. For instance, Meimei was sent to a weekend English class partly because her mother was aware of and took into consideration her husband's strong wish that their daughter master English at an early age. A few fathers who actively learn about scientific methods of childrearing, such as Xinxin's father, have more say in the decision-making and are more influential on how the child is raised.

In contrast to young mothers, grandparents generally lack power and voice in the decision-making and discussions on childrearing issues. Most of the time, grandparents do not participate in decisions related to their grandchildren's formal education. In Meimei's family, for instance, the mother never consulted with the grandparents while selecting a kindergarten or talent-cultivating programs. In her view, the grandparents were neither interested in nor knowledgeable about these issues. In other families, grandparents may express their opinions, but they are rarely considered. For instance, Grandma Liu objected to her daughter's idea of sending her granddaughter to talentcultivating classes because she believed they were too expensive and not worthwhile. Her daughter offered a few reasons, and although she was not convinced, Grandma Liu stopped arguing.

Grandparents normally take full charge of the household chores that they perform, such as choosing what to cook for the family meals. In order to ensure that everyone eats well, many grandparents will attentively solicit suggestions from other family members. Zhizhi's grandma usually asked her daughter and son-in-law what they wanted to eat the next day. She found it easier if they gave a clear answer. 
However, providing proper care for the grandchildren is likely to lead to disagreements between the parents and grandparents. The "old" experiences of the grandparents are different from "new" methods supported by the young mothers. Taking clothing as an example, grandparents often worry that the child is not wearing enough while mothers believe wearing too much is a bigger problem. Young mothers are more likely to win these arguments since they are supported by scientific evidence. Some grandparents gradually learn to ask for opinions from the parents when they take care of the grandchildren. For example, Grandma Luo was thinking of putting fewer clothes on her granddaughter because it was getting warmer. She nevertheless first checked with her daughter, "Should I change to another coat for the child? If you think it's fine, I will do that; if you believe it is still cold I will not."

If the grandparents are able to prove their old experiences are more effective than new methods, they tend to obtain more authority and autonomy in taking care of the grandchildren. For instance, Xuanxuan's paternal grandma had some training in traditional Chinese medicine. When Xuanxuan got a fever, she used indigenous methods, i.e., using a mixture of white spirit, spring onion, and Chinese medicines to wipe Xuanxuan's skin that helped bring down the fever. Xuanxuan's mother was initially suspicious; however, the grandmother's method worked well and was more effective and economical than taking the child to the hospital. Xuanxuan's grandmother was later given full charge of Xuanxuan's care when he got a fever again. However, in general, grandparents have few opportunities to prove themselves since most of these childcare arrangements do not entail quick results.

\section{A sociocultural explanation of the intergenerational power relations in childrearing}

The pattern of yan mu ci zu in the division of labor and power relations in the intergenerational parenting coalition can be attributed to sociocultural factors such as changing popular ideas of childrearing, intergenerational social mobility, and the transformation of the family structure. The emergence of modern scientific methods of childrearing, the development of the education industry, and the increasing cost of childrearing all led to a revolution in the ways families raise their children. The old experiences of the grandparents may not fit well in the new conditions of child development in contemporary times and thus become useless at the operational level. In addition, popular discourses of scientific parenting, often drawing on various and sometimes divergent theories of child development and parent skills, foreground its departure from and advantage over the traditional ways of childcare, which further devalued the grandparents' experiences in childrearing at the symbolic level. Among the interviewed families, young parents often perceived the grandparents' understanding of raising a child as outdated, defective, or even misleading, as illustrated by a quote from Xinxin's mother,

When we were little children, our parents did not know much about parenting. After the family ate together, adults went about their own business and we simply played on our own. There was no such concept as family education. My family was living in the countryside then and my parents did not have much education. ... Nowadays things are different, and their old experiences from a long time ago are not useful any more.

Some grandparents admitted that they were "out of date." Grandma Wang, for example, dressed and prepared food for her grandson, but it was her daughter-in-law 
who decided what the child should wear and eat. Grandma Wang explained, "This [arrangement] is good, because it won't bring conflicts [between me and my daughterin-law]. Everything is better and modernized now. We are outdated, and cannot keep up with the new things. We need to take things easy, otherwise it does no good."

The fact that older people lose their authority in how to raise the grandchildren illuminates the features of what Margaret Mead calls the "prefigurative culture" era. Furthermore, intergenerational social and spatial mobility inverted the relational position of the old people and their adult children in the family. Among the interviewed middleclass families, most of the young parents had achieved upward social mobility through education. Compared with their parents, they were better educated, had more income and higher social status, and were thus regarded as more knowledgeable and capable. They also had more financial, social, and cultural resources that enabled them to make better arrangements for their children. All these gave them more authority and power in childrearing. Among the families investigated, there was only one family in which the parents did not achieve upward mobility compared to the grandparents. The grandfather was a retired high-ranking military officer who received a high pension, and his son and daughter-in-law were university professors. However, the former division commander moved to Beijing in order to take care of his grandson, and the rich social and cultural resources he enjoyed in his hometown were largely compromised because of the move.

In terms of family structure, most grandparents in the 13 families left their own homes and moved into their children's homes in order to take better care of their grandchildren. ${ }^{6}$ The newly formed intergenerational family is an extension of the nuclear family of the young parents. The distinction between the parents as the masters and the grandparents as guests/helpers is clear. The fact that young mothers are positioned at the power center of the intergenerational parenting coalition is attributed to two factors associated with family dynamics. The young mother serves as the mistress of the family and assumes responsibility for all domestic affairs. In addition, handling the important affairs in child development renders them the de facto power and authority in making decisions and arrangements for their children. ${ }^{7}$

\section{Intimate power: intergenerational intimacy and the exercise of power in the family}

In the previous section, I have illustrated that in the intergenerational parenting coalition, young mothers have more power in decision-making and discourses concerning childrearing affairs. Nevertheless, young mothers do not have the institutionalized symbolic and moral resources to ensure their authority, and it is not guaranteed that all other family members, especially the grandparents, will comply with the decisions and arrangements these mothers make for their children. Yan mu ci $z u$ is a form of uninstitutionalized intergenerational power that leaves room for competition and negotiation in the family, i.e., family members may strategize to change or maintain their status in the family. In this flexible power structure, the maintenance of power relations in the intergenerational parenting coalition is intertwined with the specific pattern of intimacy established between the parents and the grandparents. Young mothers' successful exercise of power in parenting largely depends on the fact that the grandparents tolerate their marginal status and accede in the power struggle for the sake of maintaining a desirable intergenerational intimate relation. 
Tolerance and grandparents' expectations regarding intergenerational relations

The reason young parents co-reside with their parents is because they need help in childcare; their main concern is the development of the children. For the grandparents, however, helping raise the grandchildren is a part of intergenerational cooperation. By doing so, they hope to maintain a continuing mutual assistance in family affairs and emotional closeness with their offspring. When addressing the reasons why they were willing to help with childcare, most grandparents interviewed emphasized the joy of "raising a child." For instance, Grandma Zhang stated, "We, old people, enjoy staying with the little ones. This gives us something to occupy [our time]. My neighbors [an elderly couple] just live by themselves. Their son and other children all live separately. It's been rather boring for them."

It is also important for the old people to sustain mutual support with their children. They perceive looking after the grandchildren as a way of helping their own children and expect to receive assistance from their children when they are too old or sick to take care of themselves, as mentioned by Grandma Zhang:

Nowadays jobs are highly demanding and competitive for our children. ... We are still healthy; we do not have serious health problems and are able to take care of ourselves. We should support them. We do more for them now and when we are seriously ill in the future, we will count on them [for support].

Grandparents do not seek equality in the intergenerational exchange but hope to sustain an ongoing reciprocity with their children. They are well aware of the fact that the payback from their children will be delayed and depend on positive interactions between them and their offspring. As Grandma Wang said, "If we have a good relationship with our children, we will be able to have them stay around [taking care of us] in the future." She and her husband had come to an agreement:

The two of us realized a long time ago that we would stay out of our children's business since there is definitely a generation gap between us. If we express our opinion on their business, they won't listen. It will do nothing but upset us. We'd better keep our mouth shut. Whatever they say, we will just listen and not argue. Even if [we believe] they are doing it wrong when they discipline him [the grandson], we will stay silent. Too much quarreling does not make a good life.

Grandma Wang also viewed not arguing with the younger generation as a way of showing tolerance and understanding: "She [her daughter-in-law] is still young and immature. She gets anxious easily and makes a fuss. Sometimes we made some comments and then she realized that she made a mistake and that she would be more careful in the future. But other times, she would simply forget afterwards." The reason why grandparents choose to concede when disagreements come up with their children is not because they conform to the authority of the latter, but because they want to keep a peaceful relationship with their children that benefits the whole family.

The grandparents also wish to be respected and cared about by their children. The desirable intergenerational relationship they expect includes a feeling of intimacy among family members who care about one another and a sense of dignity and status 
in the family. Grandma Li took greetings and expressions of care from her son and daughter-in-law seriously: "We, old people, do not want money from you. We want nice words. For instance, when you come back home, you say, 'Oh mom, you are still up. What did you eat today? ${ }^{8}$ As simple as that." The grandparents often recalled the moments when their children expressed concern for them. Grandma Liu happily shared one such moment. One day her son-in-law noticed that the old couple planned to fix a simple lunch with noodles. He went out and bought porridge, Chinese pancakes, and two dishes for them. "I was feeling very content," Grandma Liu commented.

Respect and understanding from the younger generation are important for the grandparents as well. For Grandma Wang, filial piety meant forming an equal relationship with her children and not picking on one another. She said,

What is filial piety? It means [the younger generation] not talking back when I say something, whether I am right or wrong. I am old, a bit slow, and have bad memories, so please keep silent even if I am wrong, and do not talk back. If there is some disagreement between us, pretend to agree with me. I serve you food, drink, and take care of your daily life; so do not be fussy and make conflicts. I am not picking on you, so do not pick on me.

However, as stated in the previous section, in many families, young mothers often judged and interfered with the grandparents when they took care of the child. This not only constituted a direct challenge to the face/dignity of the grandparents but also impaired an intergenerational relationship of mutual understanding and tolerance that the grandparents sought to establish. As a result, grandparents may stop being cooperative and instead build an emotional alliance with their grandchildren as a way of challenging the maternal power.

In the interviews, many young mothers mentioned that their grandparents often undermined their efforts in disciplining the child. Many grandparents would intervene and indulge the child when they did not obey the mother's rules. For instance, Jingjing's mom did not allow her son to eat sweets, which she believed was bad for his health. Jinging was well behaved when she was present, but she later discovered his strategy:

The child is so clever that he's learned from early on when he should go to his grandparents and when he should go to his parents. He goes to the grandpa for candies and roasted sunflower seeds because the grandpa will give him what he wants. He likes candies and chocolates, and for quite a while sneaked a few every day, which I was not aware of. But he did not know to throw away the candy papers and left them in the drawer. One day I happened to open the drawer and was astonished to see a full drawer of candy papers. I asked my mom about it, who then told me the child ate one piece each day.

Apart from indulging the grandchildren by acquiescing to their demands, some grandparents also try to defend the grandchildren against the parents. When 4-year-old Doudou threw his toys everywhere, his mother asked him to put them back in the toy boxes. Doudou refused to do so and started crying and screaming. Seeing her child being unreasonable and acting up, the mother decided to discipline him. The paternal grandfather jumped in, cuddled his grandson, and said, "It's OK! Grandpa will help you 
clear up!" As some mothers reported, many children have learned to seek protection from the grandparents, crying out for their help while being disciplined or punished in order to escape punishment from their parents.

In the contemporary intergenerational parenting coalition, mothers who are responsible for the social nurturing of the child tend to train their children in accordance with the demands of the society or the ideas from modern parenting theories. In contrast, grandparents are in charge of physiological nurturing, satisfying the physiological needs of the children. They are thus prone to take the children's standpoint and empathize with them, offering emotional support when they suffer (Fei 1998). However, children are little agents who are good at catching the discrepancies between different nurturers and finding space for negotiation and manipulation (Goh and Kuczynski 2009). By acquiescing and providing defense and protection, grandparents form close alliances with their grandchildren, and together, they undermine young mothers' power. Thus, their relationship with grandchildren mattered a great deal to the grandparents. In the interviews, grandparents often offered examples of their close relationship with their grandchildren or expressed their regret that "the child is still closer to his/her mom."

\section{Managing intergenerational intimacy and the maintenance of maternal power}

The alliance between grandparents and the grandchildren obstructs the child development plans made by the young mother and impairs her managerial position in childrearing. To deal with this problem, some mothers work on their relationships with the grandparents. Specifically, they maintain their leadership in parenting by meeting the grandparents' expectations of intimate relations in the family. Qing provides a good example.

Qing was a mother of a 3-year-old girl, Yuanyuan. She worked in a travel service company as an assistant director and her husband was a vice president in a communications company. When Yuanyuan was 8 months old, Qing's in-laws, who had been living in a northern town, moved in to help with childcare. The grandmother attended to Yuanyuan's daily needs, and the grandfather took care of the household chores, preparing food for the family and cleaning the apartment. With the help of the in-laws, Qing was able to occasionally watch a movie online or enjoy an afternoon tea with friends. For the sake of Yuanyuan's development, Qing believed it was necessary to "educate" her in-laws to modernize their perceptions and behavior. Given the numerous disparities between her and her in-laws regarding how to raise a child, she prioritized her demands, stressing the most important ones. For instance, she turned a blind eye when grandparents insisted on feeding the child rather than have the child feed herself, as she preferred. When it came to issues associated with the child's logical training, however, she was rather strict and persistent. For instance, when Yuanyuan fell down, the grandparents were not allowed to comfort the child by blaming the floor (such as saying "It was the fault of the floor that our baby got hurt") since this was inaccurate. Most importantly, she did not want the grandparents to intervene when she was disciplining her daughter. She said, "I would keep reasoning with them and not give up. I won't say 'It is absolutely wrong to do this' or 'You can never do this.' Quarreling with them and confronting them does no good to your family. After all, you are all living under the same roof."

Qing paid close attention to the needs of her in-laws. Her mother-in-law had rather large feet and had difficulty finding comfortable shoes at affordable prices domestically. 
When she went to England on a business trip, Qing brought five pairs of Clarks, a footwear brand known for its comfort. Qing also joined the grandparents in their conversations about their relatives although she personally found it boring. She generously offered help when her husband's relatives needed it; she helped arrange the wedding when one of his cousins got married and housed another cousin when he came to Beijing for his visa interview. She commented humorously: "We are the 'reception office in Beijing' [for his relatives]."

Taking advantage of her job, Qing arranged a few vacation trips for the whole family. She put her mother-in-law in business class to reduce her airsickness and made detailed schedules to ensure that everyone enjoyed themselves without getting exhausted. She was quite content with her arrangement, and said, "Last time when we were in Singapore, my father-in-law [a CCP member] literally said that he had never enjoyed such good things by following the party, but now he is able to do so by following his son. ... My mother-inlaw corrected him that it was not his son, but his daughter-in-law."

When Qing was disciplining her child, her mother-in-law gradually agreed to stay in her own room. However, her father-in-law, who was used to the role of head of the house, still intervened, which sometimes ended in open conflict between the two. Qing said:

I said to the grandparents: 'If you disagree with me, we can discuss it after Yuanyuan falls asleep. We do not argue about it in front of her. We can have a family meeting to talk about our disagreements.' But it was really difficult for them. Sometimes he [the grandfather] acted out on the spot, and I got annoyed and argued with him directly. [I have to admit that] conflicts did exist, and there was no way to avoid them.

However, Qing usually approached her father-in-law after these conflicts, apologizing and seeking reconciliation. She gradually managed to persuade him to take a walk outdoors when she disciplined her child. She explained:

I am living with this family, and sometimes I have to resign myself. I am not idealistic. I am not a princess. There are things I have to yield to. Why should I initiate reconciliation with my father-in-law? It makes no sense to argue about who was wrong. Just say what you should say. After all, he is an old man. I should respect him simply for the reason of seniority. Even if he is being ignorant and stubborn, he is cleaning the apartment and preparing meals for us, right?

Qing is strategic when dealing with her relationship with her in-laws. She made it clear that she did not want to be a housewife and wanted time and space of her own. For that, she needed help from her in-laws. Although she might not feel close to her in-laws spontaneously, Qing had interacted with them according to the principles of the family from the very beginning. In her words, "If you do take them [the grandparents] as your family, how uncomfortable you will be at home!" Thus "you do whatever you should do and say whatever you should say." Her management of the intimate relations with her in-laws includes the following:

First, by buying clothing for her in-laws, taking them on family trips, and taking care of her husband's relatives, Qing properly expressed her care and mindfulness toward her in-laws and made them feel proud in front of other relatives, which in turn won a 
good reputation as being filial. Second, she partially yielded to her in-laws, giving them some autonomy when they took care of the child. Third, in dealing with conflicts with her in-laws, she adopted certain strategies, such as making ritualized apologies and having family meetings. In doing so, she showed them respect and gave them the right to express their opinions on certain family affairs. Finally, by making good arrangements for the whole family that not only satisfied but also exceeded her in-laws' expectations, she delicately managed to present herself as capable and sophisticated. With these efforts, Qing earned recognition and appreciation from her in-laws and enhanced her status in the family. Since a positive interaction was established and maintained across the generations, the grandparents received respect and care and, in turn, were more willing to be trustful and tolerant of their daughter-in-law.

\section{Weak intergenerational bonds and the intergenerational struggle for power}

An intimate relationship based on mutual understanding and consideration is crucial in the intergenerational parenting coalition but it is difficult to establish, especially in families where the coalition is formed between young mothers and their in-laws who did not have strong emotional connection before living together. In the initial stage, conflicts often occur between the young mother and her in-laws due to differences in lifestyle, habits, and even the way of speaking. To avoid conflicts, some families adopted a distancing approach. With a lack of intimate bonds across generations, young mothers may encounter more challenges in the parenting process, as revealed in the case of Xuanxuan's family.

When Xuanxuan was 1 month old, his paternal grandparents moved from their homes in southern China to help take care of the baby. This was more than 5 years ago at the time of the interview. Xuanxuan's mother, Rong, described her relationship with her in-laws as being "polite but distant." When she stayed at home during her maternity leave, she had some arguments with her mother-in-law on minor issues, which gave her the impression that "it does not work for the two of us to spend every moment together." She thus decided to minimize interaction with the in-laws in order to avoid conflicts. She went to her office every day and stayed as long as possible, although her job offered the opportunity of working from home. In contrast, the grandparents were busy in the house, cooking, washing, cleaning, and so on. Rong was fully in charge of pursuing talent-cultivating classes and arranging extracurricular activities for Xuanxuan, which the grandparents seldom asked about. When it came to Xuanxuan's birthday parties, weekend activities, and vacation trips that the parents planned for, the old couple rarely participated.

Although Rong was freed from any household chores, she often felt suppressed at home. She did not have much conversation with her in-laws at the dinner table and had little say in the affairs that her mother-in-law supervised. For instance, Rong thought that a big dinner with a lot of meat and fish was delicious but unhealthy. She suggested her in-laws to cook less but in vain. She also found herself under the surveillance of her mother-in-law in the house, which made her rather uncomfortable. Once she got some fruit for her son from the refrigerator. When she closed the refrigerator door, her mother-in-law called out, "The door is not tightly closed!" These encounters sometimes ended up in confrontations between the two women, which further cemented Rong's strategy to minimize interaction with her in-laws. 
With the help of the grandparents, Xuanxuan grew up well, quite tall and strong for his age. Rong appreciated her in-laws for their skills in childcare, but she found it hard to discipline Xuanxuan at home. If he was unwilling to follow her directions, he would simply "turn a deaf ear and refuse to listen." Rong did not consider herself to be strict; she believed in the power of encouragement. However, once in a while when she attempted to discipline him when he misbehaved, Xuanxuan would easily find shelter with the grandparents. For example, one bedtime, Xuanxuan said he was hungry. Rong believed this was simply a ploy for not going to bed so she ignored him. However, the grandmother immediately went to the kitchen and cooked for him. Xuanxuan always asked for new toys, which Rong believed was a bad habit. She made an agreement with him that he would not buy new toys for a month since he had just received a few. However, Xuanxuan went out with his grandpa and returned with new toys.

Rong tried to communicate with the grandparents. Her typical way was to announce her agreement with Xuanxuan over the dining table: "I bought quite a few things for Xuanxuan today, and we agreed that he should not get new toys this month. Please do not buy new toys for him, grandpa and grandma." It did not work at all. Rong thus had to change her strategies, taking Xuanxuan out of the house as long as possible since she was unable to give directions to her son at home. She sometimes felt helpless because her home had gradually become "just a place to sleep in."

In Xuanxuan's family, the mother and the grandparents maintained a relationship in which they were functionally cooperative but emotionally distant. This helped buffer open conflicts between the mother and the grandparents. ${ }^{9}$ However, it obstructed the possibility of establishing intimate relations in which the mother and the grandparents would be able to empathize and communicate with one another. In this "polite but distant" intergenerational relationship, the grandparents found it hard to receive care, empathy, and the emotional bond they expected from their intergenerational interactions; they were also reluctant to feel empathy and tolerance toward their daughter-in-law. Since the buffering effect of intergenerational intimacy was missing, the grandparents tended to apply the principle of unity of responsibility and power. They did not intervene in family affairs in which they were not involved, but by constantly contributing to their children's families, they accumulated moral capital, ${ }^{10}$ which they converted into total control over the housework they performed. In addition, the grandparents turned to their grandson for an emotional alliance. By fulfilling the grandson's demands, they consolidated the grandparents-grandson ties that served to maintain their status in the family.

\section{Conclusion}

Drawing on in-depth interviews and ethnographic data from urban middle-class families, I argue that intergenerational parenting coalition is a family strategy adopted by urban families in order to cope with the privatization and marketization of childcare in contemporary China. With the division of labor by gender and generation in the family, the pattern of yan mu ci zu has emerged in the organization of childcare. Young mothers act as managers of the childrearing project. Equipped with scientific parenting methods, they dominate the decision-making and discourses of childcare, make child development plans, and engage in social rearing such as intellectual cultivation and character building of the child. In contrast, grandparents join their children's family as helpers. They perform a large amount of housework and physiological rearing of the child but remain marginalized 
in the decision-making. The rise of this particular pattern of power relations is associated with modern parenting ideologies, intergenerational social mobility, and the shift in the family structure.

I further argue that yan mu ci zu is a set of fluid, uninstitutionalized power relations modified by the affection and interaction between family members. In the intergenerational parenting coalition, young mothers are more concerned about the outcome of the child's development, while the grandparents tend to value the maintenance of intimate intergenerational ties, which consist of not only duty-based exchange and assistance but also positive affection and interactions between the generations. To maintain desirable intimate intergenerational relations, the grandparents learn to be tolerant, make concessions, and yield their authority, which facilitates the exercise of power by young mothers. However, when intimate intergenerational relations fail to be established or sustained, grandparents tend to be less concessive, dissolving the young mothers' power via their emotional alliance with the grandchildren. In this sense, " $c i$ " (mercy) constitutes an emotional strategy of grandparents who seek status and power in the family. I thus use the term "intimate power" to characterize the exercise of power in the intergenerational parenting coalition. I argue that intimate intergenerational relations constitute the premise of the power relations of yan mu ci zu, mediating the individual negotiation of power in the family. The term "intimate power" highlights the specific feature of power relations in the family in which individual dignity and interpersonal intimacy are intertwined, creating tension and coordination between family members.

Scholars have discussed the dynamics between intimacy and power in the family. For instance, Wu (2009) points out that "family life is a combination of affection and politics." Familial love is the beginning and the end of family politics; however, the latter does not follow the logic of the former. The principle of family politics is that everyone seeks more power in family life or at least to be respected by other family members, which constitutes a fundamental tension between affection and politics. Wu focuses on the tension between affection and politics as he examines cases of suicide in which family relations ended. In contrast, this study looks into ongoing intergenerational collaborations though conflicts exist, which better illustrates the coordination of affection and power. I argue that in the process of intergenerational collaborations individuals may withdraw from seeking more power in the decision-making and discourse of family affairs so as to maintain a desirable intimate relationship. Maintaining a satisfying intimate relationship constitutes an important pursuit of family life and compensates for the impairment of power to a certain extent.

A number of scholars have noted an "intimate turn" in the intergenerational relationships in contemporary China. With the establishment of the urban pension and medical insurance systems, elderly people demand less financial support from their children but more communication, trust, and empathy (Evans 2010; Wang 2012). Therefore, they are willing to offer financial assistance in order to develop "negotiatory intimate relations" with their children (Zhong and Ho 2014) or yield authority and power in the process of childcare so as to maintain desirable and sustainable intimate intergenerational ties, as illustrated in this article.

By analyzing the dimension of power in the intergenerational parenting coalition, this study further elucidates the tendency toward an inversion in the power hierarchy between the parent and their adult children in intergenerational collaborations. To some 
extent, the inversion is associated with the fact that the adult children have a higher socioeconomic status than their parents. However, the formation, development, and modification of the power pattern in the intergenerational parenting coalition largely depend on the cultivation of intimate bonds by both the parents and their adult children. Highlighting the intimate bonds sheds light on the importance of bring in individual agency regarding their conception and pursuit of family life in the studies of the intergenerational relations and thus better informs the logic of practice in collaborations across generations. Future research is needed to unpack the ways in which intimate relations affect family members' pursuit of respect and justice in other forms of intergenerational exchanges and collaborations.

\section{Endnotes}

${ }^{1}$ Among the mothers, four were not employed at the time of the interview, of which only one did not plan to find a job in the near future. The other three were all considering freelance jobs in education and training or consulting, which would allow them to work and take care of their children.

${ }^{2}$ Large-scale surveys have validated the pattern of increasing expenses/consumption of childrearing. A large-scale ten-city survey found that families with children aged three to six spent 1454.92 yuan $(\approx 222)$ per month on average on preschool education. In high-income families (monthly income of 10,000 yuan or more), the expenses for preschool education reached 2583.7 yuan $(\approx \$ 394)$ per month, about $18.17 \%$ of the family income (Liu and Song 2013). Xu finds that in Shanghai families spent more on children than on parents. In families with children aged 0 to 16 years old, the annual cost of raising a child was between 13,000 yuan $(\approx \$ 1983)$ and 19,000 yuan $(\approx \$ 2896)$, accounting for $39-51 \%$ of total household expenses. The higher the family income, the more they spent on the child (Xu 2004).

${ }^{3}$ The cost increases year by year. At the time of the interview, it had reached 4200 yuan $(\approx \$ 640)$ per month.

${ }^{4} \mathrm{~A}$ small number of fathers were more involved in decision-making, however. For instance, Xinxin's father read extensively about childrearing in books or online and shared that information with the mother. This couple also regularly discussed the issues about Xinxin, although normally it was the mother who handled them. Xinxin's father explained, "We have much in common regarding our ideas about childrearing. I am more logical, and she is more emotional. Normally I tell her what to do and she will do it [with the child]."

${ }^{5}$ In a number of the interviews mothers mentioned that they had complicated feelings about the fact that their husband "did not mind spending money on the child." On the one hand, they complained that their husband simply spent money but did not know how to provide good guidance to the children. On the other hand, only when the fathers did not mind spending money were the mothers able to implement their child development plans smoothly.

${ }^{6}$ It is common in migrant families that the grandparents leave their hometown to live with their children in Beijing. Even in some Beijing resident families, some grandparents move to live with their children to provide convenient childcare.

${ }^{7}$ In traditional families women held de facto power for making important family decisions since they were responsible for performing housework and taking care of family 
members, but their power in decision-making needed formal approval from their husband, who symbolized the head of the family (Li 2010). Departing from the fact that women exercise power implicitly in traditional families, the mothers interviewed in this study had explicit power in decision making, and in most cases, they only involved their husband in the discussion or simply informed them about their decisions.

${ }^{8}$ This is a common greeting among Chinese people, which is similar to "How was your day?"

${ }^{9}$ Undoubtedly, managing a relationship that is "friendly but at a distance" is an active attempt to maintain intergenerational intimacy, a way of avoiding an unsatisfactory intergenerational relationship.

10"Moral capital" is a term coined by anthropologist Fei Wu to explain family politics. It refers to the behavior and status of an individual that is considered beneficial to the whole family. Wu argues that in family politics or power games, moral capital is an important factor that determines the winner (Wu 2009, 48).

\section{Acknowledgements}

This research is funded by the Youth Grant from National Office for Education Sciences Planning, China (全国教育科 学规划教育部青年课题). The funded project is entitled “Social views of children: A social class comparison" (大众儿 童观的社会阶层比较研究, EHA110361). The interviews with the grandparents were conducted by Tian Xia, MA student of the School of Social Development and Public Policy, Beijing Normal University, between 2012 and 2013.

I wish to make these acknowledgements if the manuscript is able to be published at the Journal of Chinese Sociology.

\section{Competing interests}

The author declares that she has no competing interests.

Received: 26 April 2016 Accepted: 28 June 2016

Published online: 03 August 2016

\section{References}

Bian, F., J.R. Logan, and Y. Bian. 1998. Intergenerational relations in urban China: Proximity, contact, and help to parents. Demography 35(1): 115-124

Chen, J. 2005. They have influenced 100 million families - ten most popular theories of Parenting in contemporary China. Chinese. Beijing: Beijing Press.

Chen, F., G. Liu, and C.A. Mair. 2011. Intergenerational ties in context: Grandparents caring for grandchildren in China. Social Forces 90(2): 571-594.

Cherlin, A.J., and F.F. Furstenburg. 1986. The New American grandparent: A place in the family, a life apart. New York: Basic Books.

Dong, Y. 2014. The discovery of parenthood: Science, gender, and class in childrearing literature during 1980's China, 27-30. Philadelphia, PA: Paper presented at the Association for Asian Studies Annual Meeting.

Evans, H. 2010. The gender of communication: Changing expectations of mothers and daughters in urban China. China Quarterly 204: 980-1000.

Fei, X. 1998. From Soil and Fertility System. Chinese. Beijing: Peking University Press.

Fong, V.L. 2004. Only hope: Coming of age under China's one-child policy. Stanford, CA: Stanford University Press.

Gilbson, P.A. 2005. Intergenerational Parenting from the Perspectives of African American Grandmothers. Family Relations 42(2): 280-297.

Goh, E., and L. Kuczynski. 2009. Agency and power of single children in multi-generational families in urban Xiamen, China. Culture and Psychology 15(4): 506-532.

Goh, E., and L. Kuczynski. 2010. 'Only children' and their coalition of parents: Considering grandparents and parents as joint caregivers in urban Xiamen, China. Asian Journal of Social Psychology 13(4): 221-231.

Goh, E., and L. Kuczynski. 2012. 'She is too young for these chores'-is housework taking a back seat in urban Chinese childhood? Children and Society 28(4): 280-291.

Guo, Y. 2001. "The logic of equality and its transformation in intergenerational relations: A case study of elderly support in rural Hebei." In Chinese. China Academics 4: 221-254.

He, X. 2009. "On intergeneration relationships in rural China: The ethical foundation of intergenerational relations." In Chinese, 84-92.

Kang, L. 2012. "Differences and similarities between generations: The emerging of new familism value." In Chinese. Youth Studies 3: 21-29.

Lamb, M.E. 2000. The history of research on father involvement. Marriage and Family Review 29(2-3): 23-42.

Li, X. 2010. Ningjia and Pojia: Women's living space and backstage power in a North China Village. Beijing: Social Science Academic Press.

Lin, G. 2009. Nation, single child, and the views of children. Chinese. Beijing: Xinhua Press.

Liu, G. 2005. "Why are the aged suffering? Analysis of family generation relation change." In Chinese. Journal of Nanchang University (Human and Social Science) 6: 1-8. 
Liu, W. 2012. "Has filial piety declined? Attitudes, behavior and influence factors on supporting old parents." In Chinese. Youth Studies 2: 22-32.

Liu, W. 2013. "The group difference of attitudes towards intergenerational support in contemporary families: Discussion on the cultural basis changing of feedback model." In Chinese. Contemporary Youth Research 3: 5-12.

Liu, Y., and Y. Song. 2013. "Survey on the family expenditure for pre-school education of 3-6 year-old children in urban families." In Chinese. Journal of Huazhong Normal University (Humanities and Social Sciences) 1: 155-160.

Luan, L. 2009. "A sociological investigation of families and childcare in transitional China." In Chinese. Hubei Social Science 8: 50-52.

Ma, C., J. Shi, Y. Li, Z. Wang, and C. Tang. 2011. "Family changes in urban areas of China: Main trends and latest findings." In Chinese. Sociological Studies 2: 182-216.

Shen, Y. 2013. Individual family (iFamily): Individual, family and nation in the process of modernization in urban China. Chinese. Shanghai: SDX Joint Publishing Company.

Shen, C., D. Li, and F. Zhao. 2009. Urban and rural families in transitional China. Chinese. Chongqing: Chongqing University Press.

Tan, T. 2010. Qiao Cun You Dao: The moral authority and social structure in rural China during the transition. Chinese. Beijing: SDX Joint Publishing Company.

Wang, Y. 2009. "Institutional reform, social transition and family change in China_an analysis of evidence from rural area." In Chinese. Open Times 3: 97-114.

Wang, Y. 2010. "Individual family, network family, and kinship circle family: From the combined perspective of history and reality." In Chinese. Open Times 4: 83-99.

Wang, Y. 2012. "Intergenerational relations in elderly support in rural and urban China: Evidence from a 2010 survey in seven provinces" In Chinese. Open Times 2: 102-121.

Wang, X. 2014. "A review on the construction of new fatherhood in Euro-American countries." In Chinese. Academic Journal of Jinyang 3: 77-81.

Wu, F. 2009. For justice: A cultural interpretation of suicide in a North China county. Chinese. Beijing: Renmin University of China Press.

Xiao, D. 2002. "The last generation of traditional mother-in-law." In Chinese. Sociological Studies 3: 79-91.

Xiong, Y. 1998. "Intergenerational relations and elderly care in urban Chinese families." In Chinese. Chinese Journal of Population Science 6: 15-21.

Xiong, B. 2008. Childhood memories: The history of children in China. Chinese. Guilin: Guangxi Normal University Press.

$\mathrm{Xu}, \mathrm{A}$. 2004. "The financial cost of childrearing: The structural change and optimizing in the social transition." In Chinese. Youth Studies 12: 1-8. 35.

$\mathrm{Xu}, \mathrm{Q}$. 2011. "A study of the intergenerational interaction of the elder people in rural China." In Chinese. Journal of Nanjing College for Population Programme Management 1: 5-10.

Yan, Y. 2003. Private life under socialism: Love, intimacy, and family change in a Chinese village, 1949-1999. Stanford: Stanford University Press.

Yan, Y. 2012. The individualization of Chinese society. Chinese. Shanghai: Shanghai Translation Publishing House.

Yang, S. 2011. "The change of urban families in contemporary China and family cohesion." In Chinese. Journal of Peking University (Philosophy and Social Sciences) 2: 150-158.

Yang, S., and C. He. 2004. "The ethics of responsibility and the family support in Beijing —an analysis based on date from the survey carried out in 1999 for the demand of the aged in Beijing." In Chinese. Journal of Peking University (Philosophy and Social Sciences) 1: 71-84.

Zheng, D., and S. Yang. 2003. "Marital relation formulary and power tactics." In Chinese. Sociological Studies 4: 96-105.

Zhong, X., and S. Ho. 2014. "Negotiative intimacy: Expectations of family relationship and filial piety among only-child parents" In Chinese. Open Times 1: 155-175.

Zuo, J., and Y. Jiang. 2010. Work and family of urban women during the transitional period. Chinese. Beijing: Cotemporary China Press.

\section{Submit your manuscript to a SpringerOpen ${ }^{\circ}$ journal and benefit from:}

- Convenient online submission

- Rigorous peer review

- Immediate publication on acceptance

- Open access: articles freely available online

- High visibility within the field

- Retaining the copyright to your article 